\title{
Sistem Pendukung Keputusan Dengan Simple Additive Weighting Dalam Pemilihan Calon Penerima Bantuan Rumah Tidak Layak Huni
}

\author{
Sudin Saepudin ${ }^{1}$, Dudih Gustian ${ }^{2,}$ Heri Firmansyah ${ }^{3}$ \\ ${ }_{1,2,3}$ Program Studi Sistem Informasi, Universitas Nusa Putra \\ Jl. Raya Cibolang No. 21 Sukabumi, Jawa Barat, Indonesia \\ ${ }^{1}$ sudin@ nusaputra.ac.id, ${ }^{2}$ dudih@ @usaputra.ac.id , ${ }^{3}$ herfi.juse@ gmail.com
}

\begin{abstract}
Abstrak
Bantuan rumah tidak layak huni adalah salah satu program pemerintah untuk menekan angka kemiskinan di Indonesia, namun permasalahan yang ada bahwa proses yang selama ini dilakukan oleh pihak Kelurahan masih dilakukan secara subyektif dengan hanya mempertimbangkan hasil survey. Oleh karena itu, bagi pihak kelurahan diperlukan suatu sistem pendukung keputusan agar seleksi dapat dilakukan secara efisien secara sistemik. Adanya metode Multiple Attribute Decission Making, menjawab semua permasalahan tersebut. Dari beberapa metode Multiple Attribute Decission Making, Simple Addictive Weighting dipilih untuk diterapkan kedalam sistem pendukung keputusan. Sistem pendukung keputusan dibuat menggunakan metode air terjun. Tujuan penelitian ini agar pihak kelurahan dapat menyalurkan bantuannya kepada yang berhak menerimanya, sehingga dengan adanya sistem pendukung keputusan berbasis web untuk memilih penerima bantuan perumahan sesuai dan objektif. Penelitian ini memberikan hasil yang cukup akurat dimana proses penyaluran yang tepat sasaran dengan data yang diperoleh dari pihak kelurahan. Sistem yang dibuat cukup memnatu pihak kelurahan dengan nilai sekitar $73.6 \%$ yang diuji oleh 10 orang responden.
\end{abstract}

Kata Kunci: Rumah Tidak Layak Huni, Multiple Attribute Decission Making, Simple Addictive Weighting, Sistem Pendukung Keputusan.

\begin{abstract}
The help of the home is not habitable is one of the government programs to suppress the poverty rate in Indonesia, but the problem exists that the process that was done by the village is still in subjectively Consider the survey results. Therefore, the town needs a decision support system so that the selection can be made by systemic efficiency. There is a method of Multiple Attribute Decision Making, answering all the problems. Of the multiple Attribute DecisionMaking methods, Simple Addictive Weighting is chosen to be applied to the decision support system. The decision support system was made using a waterfall method. The purpose of this research is so that the village can distribute its help to the right to receive it, so it is expected by the Web-based decision support system to select the recipient of appropriate and objective housing assistance. This research provides entirely accurate results were the right distribution process targets with data obtained from the village. The system was made enough to inform the town with a value of about $73.6 \%$ tested by ten respondents.
\end{abstract}

Keywords: Unqualified Houses, Multiple Attribute Decision Making, MADM, Simple Additive Weighting, Decision Support Systems.

eISSN: 2477-3255, pISSN: 2086-4884 https://doi.org/10.31849/digitalzone.v10i2. 2237 


\section{Pendahuluan}

Rumah merupakan salah satu bangunan tempat tinggal yang harus memenuhi kriteria kenyamanan, keamanan dan kesehatan guna mendukung penghuninya agar dapat bekerja dengan produktif dan dapat menggunakan sebagai tempat tinggal yang sehat dan aman bagi penghuninya [1]. Rumah sebagai salah satu kebutuhan dasar manusia menjadi kebutuhan yang harus diperhatikan karena menyangkut kesejahteraan masyarakat. Kebutuhan akan rumah layak huni semakin meningkat, namun tidak seiring dengan meningkatnya taraf hidup masyarakat ekonomi lemah yang mengharuskan hidup dalam rumah yang tidak layak huni [2].

Proses pengembangan perumahan dan kawasan bagi masyarakat agar layak huni dari tahun 2016 sampai dengan tahun 2021 terus mengalami peningkatan, dimana pada tahun 2016 sekitar 85,02, tahun 2017 naik menjadi 85,045\%, 2018 menjadi 85,06\%, namun mengalami penurunan pada tahun 2021 sekitar 86,02\% meskipun anggaran yang dikeluarkan oleh pemerintah Kabupaten Sukabumi tiap tahun mengalami peningkatan [3]. Proses penyaluran bantuan ini sesuai dengan peraturan dari peraturan Gubernur Jawa Barat no.46 tahun 2015 tentang maksud dan tujuan dengan pedoman dan pelaksanaan program dan kegiatan perbaikan rumah tidak layak huni bagi keluarga miskin dan MBR [4].

Permasalahan yang terjadi adanya perbedaan data-data di beberapa tempat sehingga sulituntuk dijadikan rujukan pihak terkait untuk melakukan pemugaran rumah yang layak di bantu. Hal ini terjadi karena terdapat persepsi berbeda antar para petugas satu dengan yang lain di dalam menentukan warga yang masuk dalam kriteria rumah tidak layak huni. Permasalahan lainnya adalah kriteria untuk pemugaran belum terumuskan dengan baik dan standar, sehingga banyak ditemukan data di petugas yang masih berbeda [5]. Terakhir pendataan warga yang membutuhkan rumah layak huni masih menggunakan cara manual, yaitu pengisian form dalam bentuk kertas yang membutuhkan waktu yang lama, sehingga menimbulkan kesulitan dalam hal menentukan kelayakan penerima bantuan secara benar dan tepat sasaran.

Beberapa penelitian terkait pernah dilakukan dalam proses penerimaan bantuan oleh beberapa peneliti Wildan Fauzi tahun 2016 melakukan penelitian penerima bantuan dana rutilahu dengan Metode Electre. Masalah yang terjadi ialah terjadinya rekap data dan kesalahan dalam penentuan penduduk yang harus diutamakan. Kriteria yang digunakan yaitu kondisi luas ruangan, kondisi jenis lantai, kondisi jenis atap, kondisi jenis dinding, kondisi sumber penerangan (listrik), kondisi tempat pembuangan akhir (wc), dan kondisi air minum. Sistem menghasilkan keluaran berupa rekomendasi calon penerima bantuan dana Rutilahu yang layak menerima bantuan berdasarkan ranking terbaik. [6]. Vickky Listyaningsih, Eko Sudrajat, Ryan Putranda Kristianto tahun 2016 melakukan penelitian penelitian pemilihan Penerima Bantuan Pebaikan Rumah Dengan Metode Weighted Product. Masalah yang tejadi dalam proses penyeleksian yang secara subyektif dan hal tersebut menimbulkan rasa ketidakadilan bagi warga calon penerima lain. Kriteria yang digunakan untuk proses seleksi yaitu dinding rumah, struktur atap, sirkulasi udara, kondisi MCK dan sertifikat tanah. Hasil dari penelitian tersebut metode WP dapat diuji kebenaran nya namun karena hasil pengambilan keputusan dipengaruhi oleh fisik dan psikis pengambilan keputusan [7]. Yunus Maulana, Heru Agus Santoso tahun 2010 melakukan penelitian penyeleksian bantuan dana rumah tidak layak huni berbasis web pada Kecamatan Kota Kudus dengan metode Topsis. Proses penyeleksian yang masih manual menjadi masalah utama yang menyebabkan penyeleksian kurang obyektif. Penelitian ini dapat diimplementasikan dengan menggunakan kriteria sesuai dengan pedoman pemilihan calon penerima rumah tidak layak huni dikecamatan kota Kudus [8]. Ikbal Jamaludin, Nono Sudarsono, Ika Mustika tahun 2014 melakukan penelitian Kelayakan Penerima Bantuan Dana Rutilahu Dengan Metode AHP. Indikator-indikator yang digunakan menjadikan penilaian kelayakan penerima RUTILAHU menjadi lebih obyektif dan efektif. Sistem penunjang keputusan yang dibuat memberikan keputusan yang tepat, cepat dan obyektif [9]. Kaisah Riski 
Zubaeti tahun 2017 melakukan penelitian Kelayakan Industri Pelatihan Kerja dengan metode Simple Additive Weighting. Penelitian ini menjelaskan tentang pemilihan tempat kerja praktek untuk sekolah menengah kejuruan yang menentukan kelayakan industri pelatihan kerja yang sesuai keahliannya, solusi dari permasalahan tersebut adalah dibuatnya sistem pendukung keputusan dengan menggunakan metode SAW sebagai metode pengambilan keputusan. Hasil dari penelitian tersebut yaitu telah melakukan pengujian kepada pakar sistem informasi dengan nilai $90,7 \%$, ahli materi pelatihan kerja dengan nilai 91,6\%, pembimbing guru dengan nilai 83,3\%, dan peserta didik dengan nilai 90,6\% Berdasarkan hasil, maka system penunjang keputusan eKTP sangat layak untuk digunakan [10].

Penelitian ini dapat memberikan solusi dalam memberikan rekomendasi bagi pihak terkait dalam memutuskan masyarakat yang berhak dan tidak dalam penyaluran bantuan rumah layak huni agar tepat sasaran.

Selain itu dapat member manfaat bagi pihak pemerintah selain tepat sasaran, juga dapat memberi semangat khususnya bagi penerima bantuan agar termotivasi untuk giat bekerja dan tidak selamanya bergantung pada bantuan Pemerintah. Dapat juga bermanfaat bagi Pemerintah pusat dalam memonitor proses penyaluran bantuan ke tiap daerah dengan baik dan sesuai prosedur yang ditetapkan.

\section{Metode Penelitian}

\subsection{Lokasi Penelitian}

Lokasi yang menjadi tempat penelitian yaitu Kelurahan Surade berada di kabupaten Sukabumi.

\subsection{Populasi dan Sample}

Populasi pada penelitian ini yaitu data warga calon penerima bantuan rumah tidak layak huni yang berada diruang lingkup Kelurahan Surade Kabupaten Sukabumi dengan sample sebanyak 76 warga calon penerima bantuan rumah tidak layak huni.

\subsection{Tahapan Penelitian}

Dalam melakukan penelitian ini terdapat beberapa tahapan yang telah dilakukan antara lain Indentifikasi Masalah

Identifikasi maslah yang akan dilakukan dalam mengidentifikasi masalah kemudian membuat perencanaan, perumusan masalah, perumusan metode dan solusi.

a. Pengumpulan Data

Pengumpulan data dimulai dari studi pustaka, wawancara narasumber, kemudian observasi dan pengumpulan data dokumentasi yang berkaitan dengan penelitian.

b. Implementasi Metode Simple Additive Weighting.

1. Menentukan nilai rating normalisasi.

2. Menentukan preferensi Vi atau nilai akhir.

c. Implementasi Sistem Pendukung Keputusan

Mengimplementasikan metode penelitian kedalam sistem pendukung keputusan berbasis website, dengan menggunakan model waterfall sebagai perancangan sistem.

d. Pengujian Sistem

Tahapan akhir dari penelitian ini adalah menguji sistem yang sudah dibuat menggunakan blackbox testing dan perhitungan skala likert untuk mengetahui tingkat kelayakan sistem dalam membantupengambilan keputusan. 


\section{Hasil dan Pembahasan \\ 3.1 Hasil Penelitian}

Hasil penelitian berisi implementasi penerapan metode Simple Additive Weighting (SAW) di dalam sistem pendukung keputusan calon penerima bantuan rumah tidak layak huni di Kelurahan Surade. Sistem pendukng keputusan di dapat dari analisa dan desain sistem pada bab sebelumnya. Data hasil penelitian dimasukan secara terkomputerisasi dalam bentuk sistem pendukung keputusan yang dibangun menggunakan bahasa pemrograman PHP dan MySQL sebagai database.

\subsection{Perhitungan Metode SAW}

Dalam perhitungan metode SAW, tahapan awal yaitu melakukan normalisasi nilai rating, berikut adalah nilai rating calon penerima bantuan rumah tidak layak huni.

$$
A=\left[\begin{array}{ccccc}
20 & 40 & 100 & 40 & 100 \\
60 & 100 & 60 & 20 & 60 \\
80 & 100 & 20 & 20 & 20 \\
60 & 100 & 40 & 20 & 40
\end{array} \mid\right.
$$

Kemudian dilakukan perhitungan normalisasi dengan persamaan sebagai berikut.

$$
\begin{aligned}
& \mathrm{R}_{1}=\frac{20}{\max (20: 60 ; 80 ; 60)}=\frac{60}{80}=0,25 \\
& \mathrm{R} 2_{1}=\frac{60}{\max (20: 60 ; 80 ; 60)}=\frac{80}{80}=0,75 \\
& \mathrm{R} 3_{1}=\frac{80}{\max (20: 60 ; 80 ; 60)}=\frac{60}{80}=1 \\
& \mathrm{R} 4_{1}=\frac{60}{\max (20: 60: 80 ; 60)}=\frac{60}{80}=0,75
\end{aligned}
$$

Selanjunya mencari nilai preferensi Vi sebagai nilai akhir. Dengan perhitungan sebagai berikut.

$$
\begin{aligned}
& \mathrm{V} 1=(0,25 * 50)+(0,4 * 15)+(0,2 * 20)+(1 * 5)+(0,2 * 10)=29.5 \\
& \mathrm{~V} 2=(0,75 * 50)+(1 * 15)+(0,33 * 20)+(0,5 * 5)+(0,33 * 10)=64.9 \\
& \mathrm{~V} 3=(1 * 50)+(1 * 15)+(1 * 20)+(0,5 * 5)+(1 * 10)=97.5 \\
& \mathrm{~V} 4=(0,75 * 50)+(1 * 15)+(0,5 * 20)+(0,5 * 5)+(0,5 * 10)=70
\end{aligned}
$$

Perhitungan ini dilakukan hingga data ke-76 dengan tahapan yang sama.

\subsection{Perancangan Sistem}

Menggunakan model Waterfall, tahapan dari model Waterfall antara lain :

a. Analisa kebutuahan yang terdiri dari analisa kebutuhan fungsionaldan analisa kebutuhan non fungsional.

b. Perancangan sistem menggunakan model Unified Modeling Language (UML) dan perancangan tabel database, berikut ini perancangan sistem pendukung keputusan menggunakan UML : 
1. Use Case Diagram

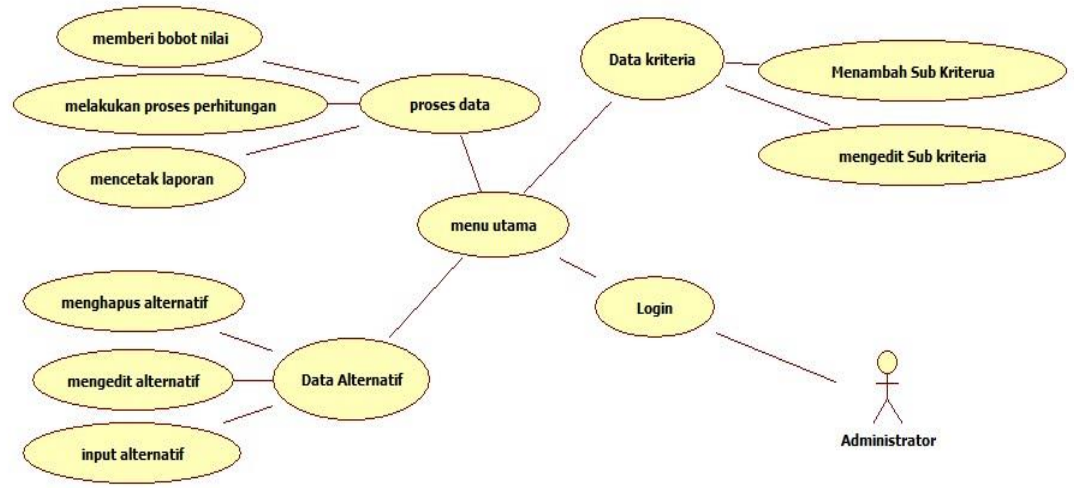

Gambar 1. Perancangan diagram use case admin

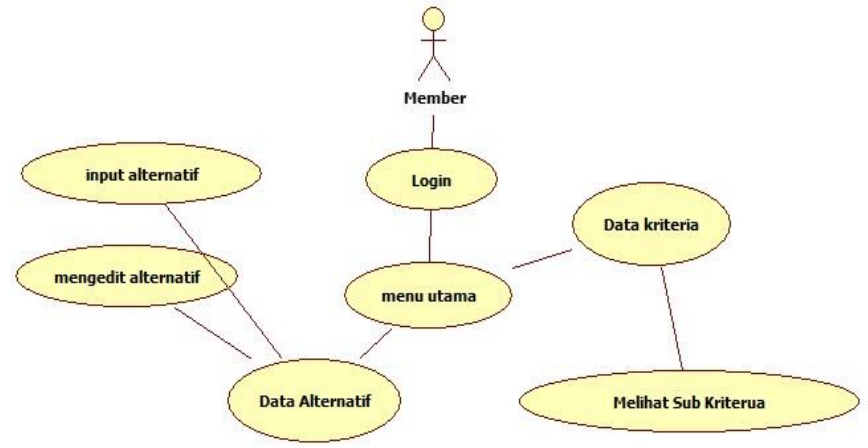

Gambar 2. Perancangan diagram use case member

2. Class Diagram

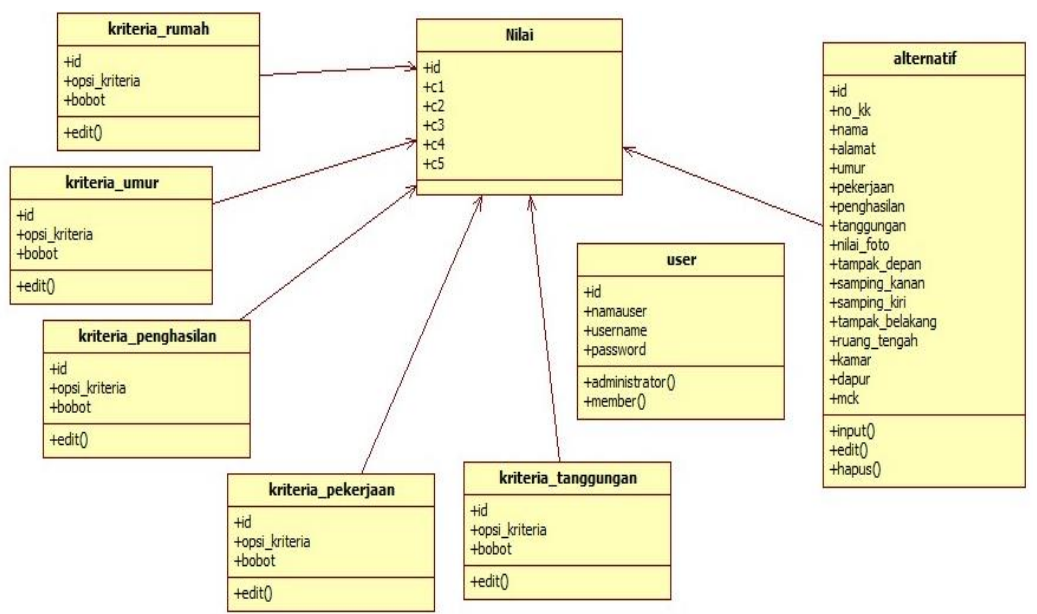

Gambar 3. Perancangan diagram class 
c. Pengkodean dan Implementasi menggunakan bahasa pemograman PHP dan MySQL.

d. Testing Aplikasi menggunakan blackbox testing dengan membagikan aplikasi kepada pengguna untuk ditest sesuai dengan fungsional aplikasi.

\subsection{Implementasi Sistem}

Implementasi sistem merupakan hasil dari analisis kebutuhan dan desain sistem yang telah diuraikan pada bab sebelumnya dalam bentuk model UML ( Unified Modeling Language ).

Berikut ini beberapa antarmuka hasil implementasi sistem.

a. Login

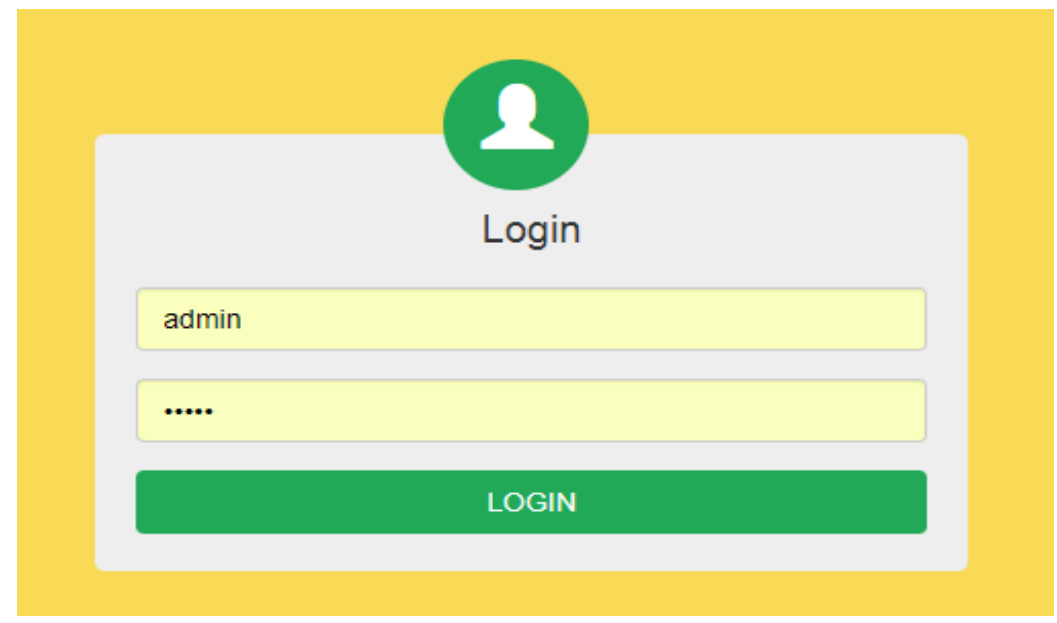

Gambar 5. Tampilan Login

b. Proses

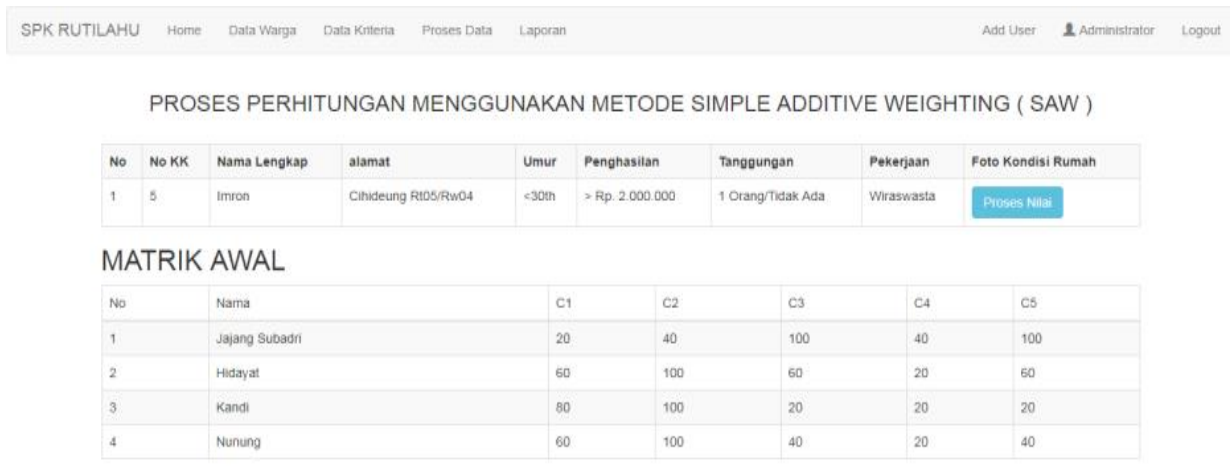

MATRIK NORMALISASI

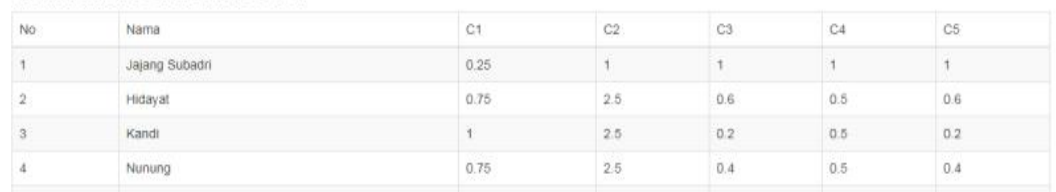

Gambar 6. Tampilan Proses 
c. Laporan

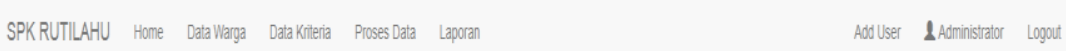

DATA WARGA PENERIMA BANTUAN RUMAH TIDAK LAYAK HUNI

KELURAHAN SURADE

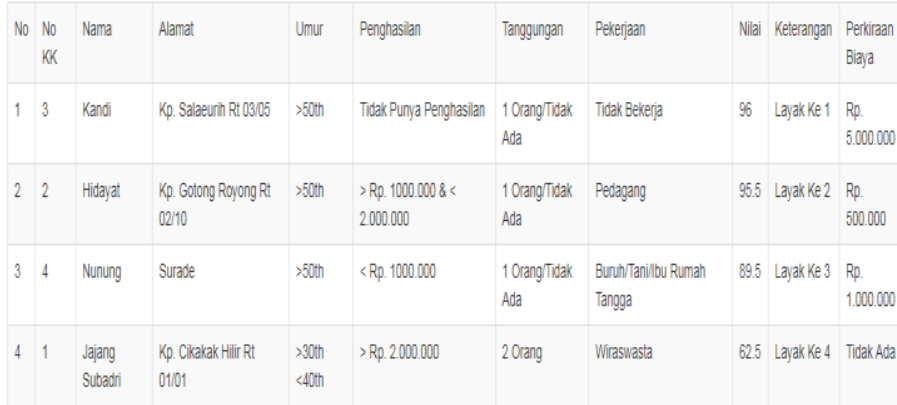

Gambar 7. Tampilan Laporan

\subsection{Hasil Pengujian Sistem}

Setelah dilakukan pengujian sistem pada aplikasi web sitem pendukung keputusan dengan menggunakan blackbox testing, mendapatkan hasil sebagai berikut :

Tabel 1. Hasil Pengujian Sistem

\begin{tabular}{|l|l|c|}
\hline \multicolumn{1}{|c|}{ Item Uji } & \multicolumn{1}{|c|}{ Detail Uji } & Hasil Uji \\
\hline Login & Melakukan login & Sesuai \\
\hline Data Warga & $\begin{array}{l}\text { Mengelola Data warga (Menampilkan, } \\
\text { Menambah, Menyimpan, Mengedit, dan } \\
\text { Menghapus). }\end{array}$ & Sesuai \\
\hline Data Kriteria & $\begin{array}{l}\text { Mengelola Data Kriteria (Menampilkan, } \\
\text { Menambah, Menyimpan, Mengedit). }\end{array}$ & Sesuai \\
\hline Proses & $\begin{array}{l}\text { Menambahkan nilai akhir kriteria dan } \\
\text { mengetahui hasil perhitungan metode SAW } \\
\text { bekerja sesuai dengan perhitungan manual. }\end{array}$ & Sesuai \\
\hline Laporan & Melihat dan mencetak laporan & Sesuai \\
\hline
\end{tabular}

\subsection{Pembahasan}

Pada penelitian ini pembahasan berisi mengenai data warga calon penerima bantuan rumah tidak layak huni yang akan diterima berjumlah 5 warga calon penerima bantuan rumah tidak 
layak huni baru berdasarkan dari hasil perhitungan metode SAW. Serta hasil koresponden untuk sistem pendukung keputusan calon penerima bantuan rumah tidak layak huni.

\subsection{Analisa Calon Penerima Bantuan Rutilahu}

Berdasarkan studi kasus calon penerima bantuan rumah tidak layak huni di Kelurahan Surade, calon penerima bantuan rumah tidak layak huni diambil dari 76 data dengan proses penerimaan bantuan menggunakan perhitungan metode Simple Additive Weighting (SAW). Diketahui bahwa calon penerima bantuan rumah tidak layak huni yang akan diterima merupakan 5 besar dari nilai tertinggi yang sudah dirangking menggunakan metode SAW. Berikut ini tabel data calon penerima bantuan rumah tidak layak huni yang mendapatkan 5 nilai tertinggi.

Tabel 2. Data 5 Rangking Terbesar penerima bantuan

\begin{tabular}{|l|l|l|}
\hline Nama Warga & Nilai Akhir & Peringkat \\
\hline Titi & 86,67 & 1 \\
\hline Uas & 86,67 & 2 \\
\hline Kandi & 76,67 & 3 \\
\hline Hodijah & 76,67 & 4 \\
\hline Isa & 66,67 & 5 \\
\hline
\end{tabular}

Berdasarkan perhitungan metode SAW diatas pada peringkat 5 besar terdapat beberapa kesamaan pada nilai akhir, akan tetapi pada keseluruhan perhitungan metode SAW pada peringkat 5 besar tidak begitu berpengaruh karena hanya peringkat 5 besar saja yang akan di ambil sebagai calon penerima bantuan rumah tidak layak huni. Secara lebih rinci, persamaan nilai akhir pada perhitungan metode SAW ditampilkan pada gambar 7 berikut.

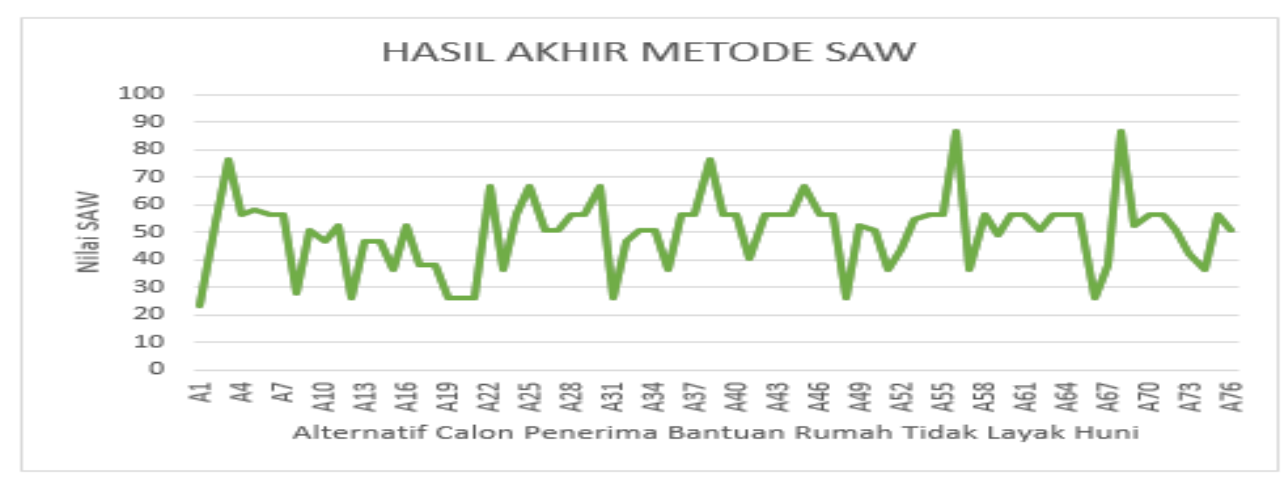

Gambar 7. Grafik Perhitungan Nilai Akhir

\subsection{Pengamatan Perangkingan Metode SAW}

Dari hasil perhitungan yang dilakukan dari keseluruhan data berjumlah 76 data, terdapat ada beberapa persamaan nilai akhir seperti contoh pada tabel 2 diatas diketahui ada beberapa masing - masing alternatif memiliki nilai akhir yang sama yaitu 86.67 dan 76,67, berdasarkan pengamatan metode SAW dapat disimpulkan bahwa adanya persamaan hasil perhitungan tersebut dipengaruhi oleh nilai alternatif kriteria, nilai bobot kriteria serta proses perhitungan metode SAW, akan tetapi pada kasus ini peringkat yang dipilih adalah berdasarkan dari nomer form terlebih dahulu sehingga diperingkat ke-satu dan selanjutnya secara berurutan, adapun 
kriteria tambahan untuk menentukan nilai yang sama akan ditentukan oleh stackholder atau pemangku kebijakan pada instansi terkait.

\subsection{Hasil Pengujian Sistem oleh Pengguna}

Pengujian Sistem dilakukan dengan membagikan kuisioner kepada 10 orang responden (5 Ahli IT dan Staff Kelurahan ) bertujuan untuk menilai seberapa besar kelayakan sistem yang dibuat terhadap manajemen sekolah. Berikut ini gambar 8. Skala kelayakan prosentase hasil uji coba oleh pengguna dengan skala likert. Dari hasil tersebut diketahui hasil pengujian oleh staff kelurahan mendapatkan hasil 73,6\% responden, sedangkan untuk pengujian oleh ahli IT mendapatkan hasil $65,6 \%$ responden.

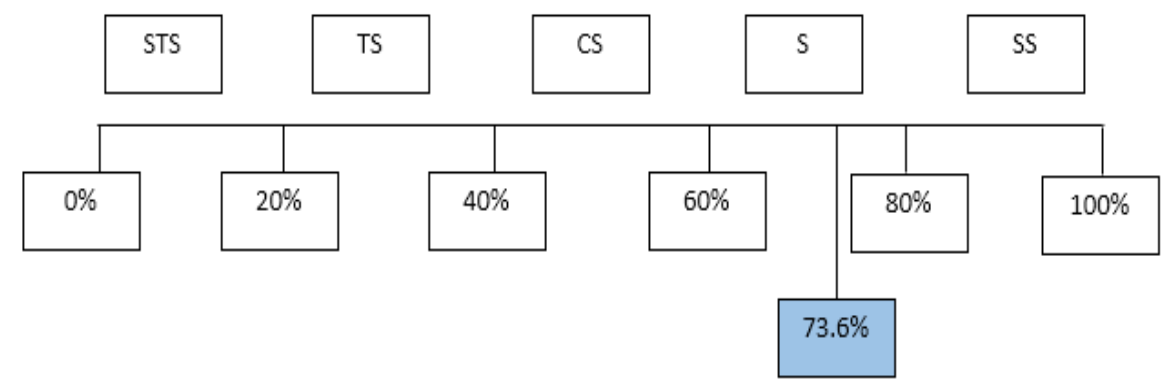

Gambar 8. Skala kelayakan presentase hasil uji oleh pengguna

\section{Kesimpulan}

Penerapan metode SAW dalam sistem pendukung keputusan penerimaan calon penerima bantuan rumah tidak layak huni di Kelurahan Surade ini dapat diterapkan dan memiliki tahapantahapan tertentu. Dimulai dari mencari nilai normalisasi yang diambil dari nilai bobot sub kriteria dengan membagi setiap nilai bobot sub kriteria dengan nilai bobot sub kriteria yang paling terbesar (maksimal) di masing - masing kriteria untuk jenis kriteria benefit (max), sedangkan untuk jenis kriteria cost (min) adalah kebalikannya yaitu dengan membagi nilai sub kriteria dengan yang paling terkecil (minimal) di masing-masing kriterianya. Kemudian langkah selanjutnya adalah mencari nilai preferensi $\mathrm{V}$ sebagai nilai akhir yaitu dengan mengkalikan nilai sub kriteria yang sudah di normalisasi dengan nilai bobot kriteria yang sudah ditentukan sebelumnya di masing - masing kriteria. Dari hasil pengujian kelayakan sistem bahwa pengujian yang dilakukan oleh pengguna dan pengujian oleh ahli IT mendapatkan hasil $73.6 \%$ dan $65.6 \%$. maka dapat disimpulkan berdasarkan perhitungan skala likert sistem tersebut dapat membantu dalam proses manajemen pemilihan calon penerima bantuan rutilahu serta secara teknis dapat membantu pengimplementasian sistem.

\section{Daftar Pustaka}

[1] Ahmad Abdul Chamid, "Penerapan Metode Topsis untuk Menentukan Prioritas Kondisi Rumah". Jurnal SIMETRIS, Vol 7 No 2 November 2016.

[2] W. Fauzi, "Sistem Pendukung Keputusan Penerima Bantuan Dana Rutilahu dengan Menggunakan Metode Electre ". Seminar Nasional Teknologi Informasi dan Komunikasi 2016 (SENTIKA 2016). 
[3] Rencana Strategis Perangkat Daerah, Dinas Bina Marga, Kabupaten Sukabumi 20162020.

[4] Peraturan Gubernur Jawa Barat tentang Pedoman program perbaikan rumah tidak layak huni, nomor 46 tahun 2015.

[5] Ahmad Jazuli, et. al. "Sistem Pendukung Keputusan untuk Penentuan Rumah Tidak Layak Huni di Cangkring Rembang Kecamatan Karanganyar Demak". Prosiding SNATIF Ke -4 Tahun 2017.

[6] W. Fauzi, “ Sistem Pendukung Keputusan Penerima Bantuan Dana Rutilahu dengan Menggunakan Metode Electre ". Seminar Nasional Teknologi Informasi dan Komunikasi 2016 (SENTIKA 2016), Yogyakarta, 18-19 Maret 2016.

[7] V.Listyaningsih, H. Setiawan, E. Sudrajat, R. P. Kristianto," DSS Pemilihan Penerima Bantuan Pebaikan Rumah Dengan Metode Weighted Product”. Seminar Nasional Teknologi Informasi dan Multimedia, 6-7 Februari 2016.

[8] Y. Maulana, H. A. Santoso, " Sistem Pendukung Keputusan Penyeleksian Bantuan Dana Rumah Tidak Layak Huni Berbasis Web Pada Kecamatan kota Kudus dengan Metode Topsis “.Fakultas Ilmu Komputer, Universitas Dian Nuswantoro 2010.

[9] I. Jamaluddin, N. Sudarsono, I. Mustika, " Sistem Penunjang Keputusan Kelayakan Penerima Bantuan Dana Rutilahu Dengan Metode AHP “. Seminar Nasional Informatika 2014.

[10] K. R. Zubaeti, "Simple Additive Weighting Method in the Development of a System Assessing the Feasibility of Job Training Industry ".Indonesian Journal of Informatics Education, December 2017, Volume 1, Issue 2 Paper 13 pp. 17 -28. 